\title{
Study on the College Public Basketball Teaching System under the background of Network
}

\author{
Haitao Lan ${ }^{1, a}$, Lingjie Guan ${ }^{1, b}$ \\ ${ }^{1}$ Nanchang Institute of Science \& Technology, Nanchang, Jiangxi, 330098 \\ ${ }^{a}$ email, ${ }^{b}$ email
}

Keywords: Network Background, College Public Courses, Basketball Teaching System

\begin{abstract}
With the continuous development of technology, computer internet technology gradually began to spread, especially in the field of education. One important component of the structure at the moment the background information network, the network has become a modern teaching in the university indispensable. Through the internet, enables the traditional teaching model has been changed to improve the efficiency and quality of modern teaching in colleges. However, with respect to language, mathematics, and many other courses, the college public education system has been the subject of basketball have not have the appropriate network-based teaching system. In this paper, a brief analysis of the current situation in the network age college public basketball teaching system, and on this basis, the teaching system of Public Basketball Teaching Process under the Network Background Construction in depth, hoping for the college public basketball Teaching Efficiency of China and enhance the quality of teaching to bring some help.
\end{abstract}

\section{Introduction}

With the continuous development of the education sector, public basketball program began to emerge in the teaching system. Basketball for college students, not only allows students to receive effective training, but also to develop students' team spirit to a certain extent. Therefore, as the college public basketball courses are, more and more students began their strong interest generated. But with the rising level of science and technology, the growing popularity of the Internet in the current context, the traditional public on Basketball Teaching Mode deficiencies also made significant public basketball teaching quality and efficiency had a significant impact. Between this, only the combination of modern network background, advanced computer technology to Internet College Basketball Teaching in public, establish a highly efficient education system, public colleges and universities for the moment in terms of basketball compulsory course has a very important practical significance.

\section{Resource Status of Network and Education in Colleges Basketball}

According to relevant survey, with the growing popularity of the network, as of 2012. So far, nearly 514 million Internet users in the scale of China, and the width of the access users has reached nearly 200 million, the number of mobile phone users has reached nearly 360 million, of which Internet users the average time spent online per week up to nearly 19 hours, and regardless of the number of Internet users, or the number of broadband users, both have shown a growing trend on the rise. This shows that China has more and more large-scale network. In addition, according to reports hours, many Internet users, the largest proportion of students. Thus, the students are the network development process, an important force, many students are willing to reach the network. Traditional network infrastructure mainly wired network, such as telecommunications networks. This is the advantage that the cable network that has a good infrastructure, faster speeds and more applications [1]. With the arrival of 3G, 4G era, wireless networks are also beginning to spread. Mobile phones and other mobile Internet is becoming the Internet needs to meet people important choice, but also greatly enhance the network traffic, the network has brought great role in promoting development.

Network technology innovation and development, largely contributed increasingly network 
application updates, online chat from the initial page of online shopping has gradually transformed into a diverse and the like. Increasingly rich web applications, also contributed to the network has gradually become one of daily life indispensable part of. From basketball in terms of public education, teaching basketball on network-related resources are also very numerous. Most of which are divided into two types of events and teaching. Race has abundant resources on the network, but some teaching resources are relatively small, and it teaches mostly dominated, often content is more boring, single, no participation, it is difficult to get the students sought after, most of all to the network Some watch basketball tournament.

For now, college public basketball teaching pattern is the use of large indoor and outdoor practice of combining theory approach. Wherein the interior theory mostly to teach students some of the principles and techniques of basketball, and outdoor practice is to allow students to learn the theoretical knowledge into practice, through training and experience to master the skills and more in-depth game experience [2]. Because of basketball practice teaching needs more demand, so its theoretical knowledge transfer is relatively small, and most are using the blackboard teaching approach. However, the traditional teaching venues and facilities will be affected to a certain extent. If during the process of teaching practice, inadequate or damaged facilities, and lack of space and other issues will result in basketball practice teaching can not be achieved. Furthermore, if the number of students more basketball program, each student has a different level of basketball, so it is difficult to take into account it prompted many teachers to each student and, thus, would adversely affect the quality of teaching. Coupled with the traditional blackboard teaching theoretical knowledge form, although so that students are better able to follow the rhythm, but for the students review after class caused a serious obstacle.

\section{Public Universities Basketball Teaching System Exploration under Background of Network}

Since modern network classroom teaching is hard to make the practice of sport is essentially Teaching issues are effectively addressed, especially with a variety of teaching content and more complex organizational change public basketball classroom curriculum. Therefore, exploring college public basketball network teaching platform still is the traditional mode of teaching are closely linked, mostly carried out on the basis of combining public basketball teaching distance learning network in the form of a [3]. Therefore, when the basketball network teaching platform to build, should be combined with practical option classes, club teaching mode, from the design to the traditional teaching process deficiencies be remedied angle. When it is an extension and supplement traditional teaching mode, which will bring a basketball student network teaching platform to promote students' self-learning and individualized learning can be achieved, and thus it is possible to let the school or the school network resources to be shared goal achieve.

Satellite network, ISDN lines, cable television, Internet and telephone network and other network infrastructure platforms are basketball network teaching platform during operation mainly, but also can be Java + struts technology to basketball after the network teaching platform program, with tool for development in eclipse, sql server 2005 will be applied to the database, the page using JSP, through css + div techniques for page layout [4].

Basketball teaching platform modules can be divided into three parts, one teaching module will be divided into a plurality of small modules of its content system, such as basketball overview of the basic knowledge and basic technology, prompting many small modules can form a large teaching system, complement each other, the corresponding function available to students for classroom learning [5]. Second, the interaction module, its role is to let the students during learning, to exchange their experiences with each other through the exchange of the way to make their interest in learning be promoted, so that teaching effectiveness is improved teaching basketball. Third, the management module, its role is to provide a range of basic data and management capabilities for basketball teaching platform, for example: the system registry, maintenance, and information dissemination.

First, the basic maintenance of traditional teaching mode characteristics of basketball specialized course in the theory and practice of combining the compression and improve the existing teaching 
content. By introducing network teaching college basketball to classroom teaching, teaching some of the skills to make a reference to the network gradually changing video study, and teaching materials unified arrangements and instructional videos. Furthermore, it should appropriate adjustments to other courses related to basketball section [6]. For example: fitness training, rehabilitation and health care. Introduction of basketball knowledge in the course of these courses, offers a range of network links to resources for students, not only to make the network content related learning standards has been strengthened, but also to encourage students to quickly grasp of basketball-related knowledge and skills.

\section{Conclusion}

All in all, with the popularity of modern technology and advances in Internet technology, network technology to the college public basketball teaching process, through basketball network teaching platform location, operating environment, teaching modules and curriculum system designed to promote traditional basketball teaching mode gradually change, enhance students' interest in learning, so in order to make teaching efficiency and quality in College basketball China has been further enhanced.

\section{References}

[1] Huang Sheng, Zhu Xiuying. Public Universities Basketball Teaching Reform Options [J]. Yuxi Teachers' College, 2012, 05: 60-62.

[2] Zhang Min. Setting of College Basketball Public Physical Education Curriculum Theory [J]. read and write (Education TV), 2016, 05: 34 + 134 .

[3] Li Guangguo, Zhang Qi. based on the "Group Teaching" constructed basketball "outside class integration" Course System [J]. Chinese Adult Education, 2014,17: 182-183.

[4] Tu Weimin, Liu Yanping. College Public Art Education objectives, curriculum reform and Evaluation System [J]. Jiangxi Normal University, 2014, 05: 121-125.

[5] Yang Hui. Explore Based on SEP curriculum Public English Course in Universities of [J]. Asia-Pacific education, 2016, 01: 98.

[6] Ling Qingdong, Xiu Xiaoyu, Li Yuechao. College Public Sport Practice Teaching System Construction [J]. Anshan Normal University, 2014, 06: 67-70. 